\title{
9 \\ The Meanings of Maternal Death
}

Why is it that maternal death so offends our sensibilities? Our collective sense of justice is violated when we think about women dying as they are bringing life into the world, even if we do not personally know anyone who has died this way. In Tanzania, and globally, a maternal death is not simply a straightforward event in which one woman, and possibly her child, die. The deaths leave traces on families, on health care providers, and on communities that continue to retell the most gruesome or heartbreaking accounts long after the woman herself is gone. These narratives that were discussed in the hospital ward, sanitized and transformed in the meeting room, and lovingly kept alive in homes as memories of women lost intersect with policies, documentation requirements, and care to make their marks on the minds and bodies of all those whose lives they touched. These deaths play across registers and levels, extending far beyond the individual and her family to local society, institutions, regions, the state, and the global community. They not only expose the weaknesses in a health care system but also highlight structural inequities that disproportionately affect the poorest and most marginalized in any country. In this concluding chapter, I trace how maternal death affects individuals and communities, as well as health care workers and institutions, including the hospital and the state. At a global level, there has been laudable rhetoric in support of reducing maternal mortality, but the effects have been mixed. What do persistently high levels of maternal deaths in certain regions mean for the world today? What can we learn from a poor hospital in a peripheral area of Tanzania that might help us ensure that fewer women continue to die? For Tanzanians, at each of these levels, deaths of women due to pregnancy-related causes represent a range of broken promises and hold different meanings. 


\section{MEANINGS OF MATERNAL DEATH FOR FAMILIES}

\section{AND COMMUNITIES}

In Tanzania, as in many places worldwide, women are the cornerstones of families and communities. Their domestic and agricultural labor, ingenuity, and tenacity are vital inputs that keep households together and surviving. Women often undertake backbreaking work and may struggle to procure subsistence needs for themselves and their families. But their role as mothers is often a source of great joy for them, with many expressing a desire for multiple children as sources of, and repositories for, love. Reproduction is a social imperative that also provides women with a more concrete form of security, tying men to them in ways that invoke interdependence and support, if not always affective caring. These moments of reproduction can also be highly tenuous and speculative, engendering a sense of danger during this period in which people take no outcomes for granted.

At this, the most personal and proximate level, the death of a pregnant woman can mean her children are orphaned or become neglected. Her husband mourns her death, and her female relatives prepare her body for burial. Even years later, they remember a woman lost. Some relatives search for reasons for the death in health care provider actions or negligence. Others speak of "bad luck," malevolent witchcraft, the will of God, or, for Muslims, a woman's ajal or appointed time of death. On a broader level, these deaths signify broken promises of state care that have a deep history in the socialist Nyerere era in Tanzania and still profoundly shape Tanzanian citizens' ideas about state responsibilities toward all members of society.

\section{Supernatural Deaths}

In the moral and ethical world of everyday Tanzanians, social relations and interdependence assure mutual support and survival through reciprocity and equitable distribution of resources. When social relations become imbalanced, often because of jealousy or resource accumulation, accusations or suspicions of witchcraft can proliferate. ${ }^{1}$ In the case of reproduction, there are many stories of jealous co-wives who seek to keep their husband's affections for themselves, placing magic under the beds of other wives to prevent them from becoming pregnant. In other cases, a witch may steal a woman's menstrual cloths from the clothesline to use any remnants of blood in magic against the woman. Likewise, in Rukwa, placentas are known to be a magically potent item that ill-wishers can use against a woman. Other community members throughout Tanzania told me of the importance of keeping a pregnancy hidden, never talking about it openly until it was impossible to physically hide it any longer. If others knew about the pregnancy early, they 
might cause harm to the developing fetus or the woman herself. Similarly, women and their close, trusted family members were careful not to advertise too widely that the woman was in labor and had gone to the health facility to give birth, lest an evil person try to use witchcraft to cause the baby to be stillborn or even threaten the life of the mother herself.

While in the hospital, women and their relatives often spoke of "bad luck," but it is likely that at least some of them suspected other forces were behind bad reproductive outcomes. For some, this other force was witchcraft; for others, it was the will of God or Allah. Those whose religion helped them to exclude witchcraft as a likely causal factor were apt to say that God had not seen fit for the baby to live or that it was not the right time for the child to come into the woman's world. In the case of the death of a woman, family members also said it was God's will. For some Muslim families, belief in an ajal or ajal musamma, or appointed time of death for every person, led them to believe it had been the appointed time for the woman to finish her earthly life. At other times, it is likely that relatives spoke of bad luck while suspecting the hospital or health facility of some form of negligence or malpractice. They may have been too uncertain of reporting or accountability procedures to report their suspicions, or their previous interactions with other health facilities may have left them cynical about any possible effect of reporting or made them afraid of retribution.

\section{Failure of State Care}

For individuals and communities, maternal deaths also carry with them resonances of the failure of state care. Particularly in a country with rich ideological ties to socialism and state responsibility for collective well-being, the poor functioning or absence of structures needed to prevent maternal deaths means an ultimate lack of caring, or an inability to care. These state structures include, among many others, roads and public vehicles, supply chains, and the number and quality of health care facilities and trained providers. Breakdowns in any or all of these can further open the door to a preventable death. To Tanzanian citizens living in rural areas, a maternal death in their family or community holds within its broader meaning an image of the state's lack of care for them and for their very lives.

\section{MEANINGS OF MATERNAL DEATH FOR THE HOSPITAL}

Through discourse and attendant regulations that have imposed fines on women who give birth outside the biomedical system, the power of biomedicine is instantiated over and over again, effectively creating these facilities as the only safe place for a woman to give birth. However, the increased demand for these services has outpaced the supply of skilled providers and the material goods-medications and equipment-needed to sustain biomedical practice. When Mawingu was unable to keep up, women's care suffered, effectively making the safest place increasingly 
less safe, in an ironic perversion of government and public health goals. Beyond just unintended consequences, increased demand without the necessary increase in resources made the hospital dangerous in cases when women arrived without money or relatives and when catheters, antibiotics, sutures, or anesthesia were out of stock. The maternal deaths that occurred at the hospital were not just, or only, clinical failures but administrative ones as well. Poor supply availability, inadequate staffing levels, improper supervision, oversight, or management of lowerlevel health care workers, and tenuous electricity or water supplies all undermined the hospital's authority. On the one hand, the regional medical officer (RMO) saw the increased numbers of patients as a testament to the hospital's improving quality of care and thus its reputation. On the other, the influx of pregnant women, even those without problems, combined with women who had complicated pregnancies, put great pressure on the hospital's resources and contributed to the maternity ward's ongoing high rates of death and severe morbidity.

The burden of maternity services often overwhelmed the hospital and its meager operating budget. The maternity ward was the problem child of the hospital, as represented by constant reprimands related to standard reporting and documentation violations and by accusations of vulgar or abusive language, disrespectful behavior, mismanagement, and improper comportment among the nurses. The maternity ward is a ward of exceptions, prompted by the unpredictable and unique nature of every woman's labor and birth. But the hospital administration often tried to run the maternity ward in the same way as the others. As a result, the staff members on the ward, the nurses in particular, constantly received criticism. This environment led many of the health care workers to question their value to the institution, as well as the relative merits of continuing to work at the regional hospital. Several of the nurses repeatedly spoke about a desire to transfer to new work locations in other parts of the country.

The administrators themselves faced an onslaught of new guidelines and regulations from a variety of national and international bodies and organizations. Planners and policy makers intended all of these programs to help improve clinical care, but their unintended side effects were the vast and rapid proliferation of paperwork, documentation, and bureaucratic procedures. All this biobureaucratic expansion served to shift the focus away from care work and onto paperwork, away from root causes and onto technical interventions. ${ }^{2}$

In other instances, the accountability and monitoring systems the hospital and the Tanzanian government put in place to help ensure high-quality care that met international standards actually helped to undermine care and were subverted for other, social purposes or used merely to perform effectiveness. Often NGOs or the central government imposed these monitoring or accounting techniques from above, and the health care workers on the ground at Mawingu tried to make space for themselves and their lived realities in between the lines of the graphs and in the blanks of the forms and logbooks. In the end, the data making their way to the 
central government were highly unreliable, produced by important social histories that were concealed by the "objective" numbers on the page.

This evidence suggests that institutionalizing birth is not, in and of itself, the solution to reducing maternal deaths in any setting. Clearly, many of the ways in which the system in the Rukwa region and Mawingu Hospital was undermined and perverted, to the detriment of high-quality, guideline-compliant care, concerned a level of scarcity that was deeply engrained in and entangled with the rapid expansion of biomedicine in Tanzania. Through efforts such as reducing the training time for enrolled nurses (ENs), the government sought to improve services by increasing the absolute number of skilled providers. However, the real result was the proliferation of new graduates who had official certificates, book knowledge, and little else in the way of problem-solving skills or training in handling obstetric emergencies. In a similar move that privileged certificates and official qualifications over hands-on experience, President John Pombe Magufuli ordered a certificate verification exercise in 2017 that resulted in many health care personnel being fired for fake qualifications. The government's fetishization of certificates resulted in an even greater shortage of skilled health care workers throughout the country. The wrong targets often became the point of focus because of their easier accessibility. It often appeared that for the government doing something took precedence, regardless of the action's unintended consequences. In the same vein, the ongoing fines for women who gave birth at home, and levied against those who assisted them, again reinforced the government's emphasis on and fetishization of papers-training certificates-despite the demonstrable knowledge of local midwives and the lack of knowledge of many new ENs who had made it through the government's expedited training programs. Quick fixes such as these continued to undermine the system and the care available to women.

The government must advance beyond rhetoric and draconian punishments that prevent women from accessing plural forms of care when the proposed alternative, birth in biomedical institutions, systematically disempowers both women and those health care workers meant to be assisting them and protecting their lives in times of emergency. Mawingu itself was a flawed institution, struggling with competing demands and the proliferation of government-imposed bureaucratic guidelines, but it found itself in a much more broadly dysfunctional system, the country's health care sector as a whole. Within this context, the individuals at the hospital, and the hospital as an organization, sought to make do and provide care that was good enough. Guided by codified nursing ethics of compassionate, selfless caring, medical ethics of doing no harm, and morals related to the interdependence of people in the broader social community, nurses and doctors at Mawingu battled deaths that unfolded and transpired at the crossroads of constant negotiation and local norms of everyday ethics. Pervasive scarcity often undermined their efforts to improve maternal health outcomes, but until the central government prioritizes solving supply chain problems and improving the candidate 
pool for nursing training, for two examples, hospital birth will remain an incomplete solution to the problem of decreasing the deaths of pregnant women.

\section{MEANINGS OF MATERNAL DEATH FOR THE REGION}

I initially decided to visit the Rukwa region after reading the 2010 Demographic and Health Survey published in 2011, just as I was beginning graduate studies. The region, of which I had never heard, ranked in the bottom five of what were, at the time, twenty-one mainland regions on all measures related to maternal, reproductive, and child health. The statistics there provided little idea of causes behind the region's poor performance on nearly all these indicators. The numbers could tell me only that 69.6 percent of women were still giving birth outside biomedical facilities. Some 36.8 percent (13.4 percent in the 2015 report) of these were with relatives; another 31.1 percent (18.2 percent) percent with local midwives, the wakunga wa jadi; and a mere 29.5 percent (64.2 percent in 2015) percent with a skilled attendant - that is, in a biomedical facility. ${ }^{3}$ While no one ever explicitly linked their employment in the region to this report, which the country (aided by outside organizations) publishes every five years, many of the medical officers (that is, the MDs) and regional officials told me they had begun their work in Rukwa in late 2011 or early 2012. For those who had had long careers in the region, these statistics and the region's relatively poor performance surely had come as no surprise.

Another legacy from the Nyerere era is that government employees have long been sent to regions other than their regions of origin. Friends have explained to me that this was Nyerere's strategy for preventing ethnic tensions and maintaining peace in the country. This system of being assigned a work location also helps to ensure that people are available to work in remote or otherwise less desirable locations. Given a choice, many people would elect to work in the main urban centers, often where they did their training. For health care workers posted to Rukwa, the region's reputation as inhospitable and as a home to witches and powerful healers intimidated many.

Every day on the hospital maternity ward, in morning meetings with the regional medical officer, and in maternal death audit meetings, the health care providers and administrators worked to advance a new image of their region and combat its old one on the national stage. For several years, the White Ribbon Alliance of Tanzania focused on the Rukwa region, drawing national-level attention to the poor quality of health care and facilities there (figure 16). The outcome was support and funding, but the region also became the face of maternal mortality and subpar services at the national level. The deaths of these women had come to represent the backwardness of the region, a region in which people, as Dr. Joseph told me on my first visit in 2012, were "still sleeping." The regional commissioner, the highest government official in the region, Engineer Stella Manyanya, also spent a great deal of time 


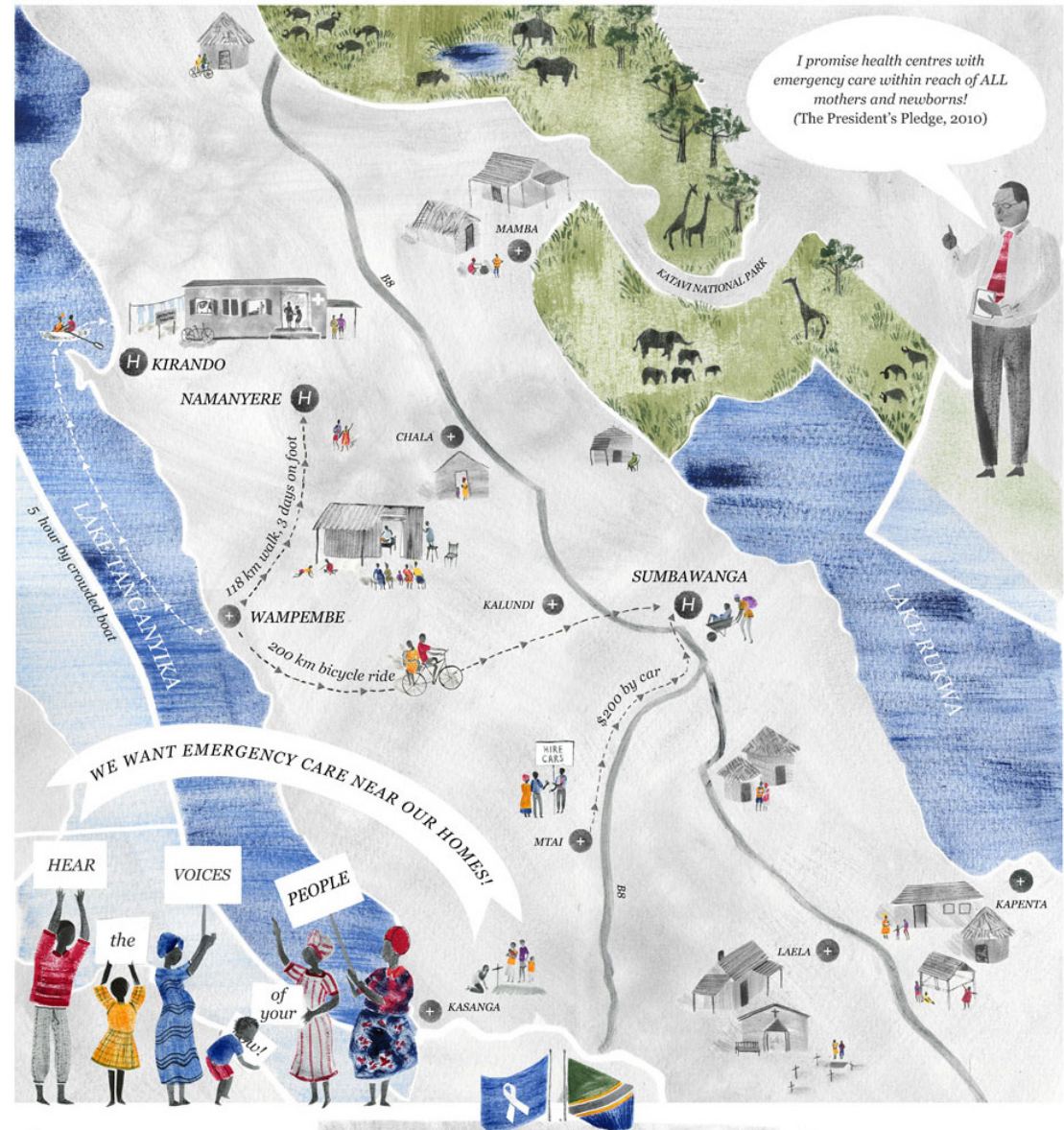

\section{† HEALTH CENTRE}

In Rukwa, Tanzania, there are NO Health Centres that can provide Full Emergency Care. As a result, women in labour have to undertake long journeys to get the care they need.

Only one third of women give birth with medical help.
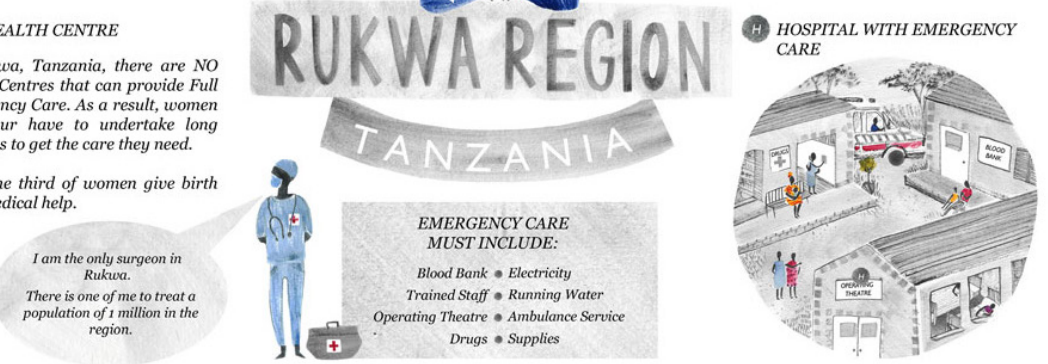

FIGURE 16. Illustration of the Rukwa region from the White Ribbon Alliance Campaign from 2013 to 2015 . The figure of the doctor is saying, "I am the only surgeon in Rukwa. There is one of me to treat a population of one million in the region." Copyright White Ribbon Alliance; illustration by Hannah Bailey. 
talking about and publicly committing to reducing maternal and neonatal deaths in her region. As the RMO related in the maternal death audit meeting in which he spoke of the importance of collecting accurate, timely statistics on maternal death, these numbers came to shape the reputation of the region in front of Parliament at the highest levels of national governance. Being able to cite declines in maternal deaths in the region proved to national leaders that the Rukwa region and its new administrators were making progress and were properly engaged in the transformative practices of maendeleo, or development, that would inevitably lead the nation to greater success as a model of progress and improvement.

\section{MEANINGS OF MATERNAL DEATH FOR THE STATE}

The promise of health care services for Tanzanian citizens originated as part of the fundamental goals of Nyerere's postindependence socialist state. In that era, the minister of health celebrated health care workers as crucial actors in the nation-building project. Writing to them in a memo dated May 18, 1964, just shy of one month after Tanganyika's unification with the island nation of Zanzibar to create the modern Tanzanian state, Minister of Health Bryceson wrote of the role of health care workers in Nyerere's first Five-Year Development Plan. He described how their formal employment in health care did not exempt them from nation-building activities such as working on a communal farm, building a road, or teaching others to read; this was their personal role. For their professional roles, Bryceson ends his memo by saying: "We are responsible for the health of the nation. The attainment of the broad aim of an increase in life expectancy is dependent upon our efforts. The very target of an improved standard of living is dependent to a large extent on the success of our teaching. I know that our medical workers, of all grades both in the Ministry and in the Voluntary Agencies, are already hard worked. Nevertheless, I am asking for more time, more effort." 4

This rhetoric, which invokes providers as key actors in nation building, imbued them with a sense of purpose and responsibility that those currently working do not feel as strongly. The more diffuse twenty-first-century rhetoric of development and human rights simply does not resonate as strongly on the local level and therefore is not the same motivator for working hard under difficult conditions. A nurse who had started her career under Nyerere said, "Work accountability, people were really working very hard. People had respect and they had love. That is different from what you see [these days]." Some others also told me they felt that during Nyerere's time the health care facilities had been better stocked with the supplies that were available during that period and that, overall, health care providers had been more focused on providing care instead of trying to make money. Enriching oneself for personal, rather than national or community, profit was antithetical to the mission of Nyerere's Ujamaa. 
In this internally facing mode, the persistent high rates of maternal deaths represent an unfulfilled promise of the Nyerere era, when the state valorized and valued health care workers. Even those Tanzanians who are too young to remember the socialist period or were born after Nyerere had already stepped down from the presidency continue to cling to the idea of state care for its citizens rooted in this era. So too, the national television stations continue to play excerpts from Nyerere's speeches every night as part of the news hour. Nyerere, Baba wa Taifa, father of the nation, still watches over every government office, peering down at workers from his portrait always given pride of place next to the current president and the office clock. The current president, John Pombe Magufuli, has very effectively drawn on elements of Nyerere's rhetoric to marshal support for contemporary state-building projects, proving that this ideology still resonates.

In a more externally facing mode, maternal mortality continues to play a role in state deservingness for aid. Paradoxically, reducing the maternal mortality ratio proves the country is doing well, complying with international guidelines and donor demands, and improving citizens' quality of life while, at the same time, suggesting a waning need for outside assistance. Stubbornly high rates, though, signal the country's ongoing status as a "developing" country dependent on aid and outside expertise. Maternal mortality continues to be a significant indicator by which countries throughout the world measure each other and relative success. Such indicators are essentially proxies for larger measures of state success, including economic and political stability, administrative acumen, and the realization of the globally recognized human right to health. Even in high-income countries, such as the United States, maternal and neonatal death rates signify inefficiencies, inequities, and imbalances.

Tanzanian national priorities, in relation to maternal health care and derived from global guidelines and recommendations, now emphasize place of birth and access to biomedical care over all other considerations, driving more and more women to these places without commensurate investment in ensuring that facilities are capable of taking on these new clients. This drive has led to overcrowding, worsening scarcity, provider burnout, and inattentive (at best) care, while also limiting women's autonomy through punitive restrictions on home births and home birth providers. ${ }^{5}$ It is difficult not to conclude that misplaced emphasis may be prohibiting further declines in maternal deaths in places such as Tanzania, but ultimately it is far easier to tell people to go to the hospital than it is to uproot structural inequities producing maternal deaths and severe morbidity.

\section{MEANINGS OF MATERNAL DEATH FOR THE GLOBAL COMMUNITY}

Globally, defining who has a right, or the legitimacy, to make claims on care and on what quality of life has become a significant component of political agendas. Poor 
women in rural corners of the low-income global South have achieved recognition, biolegitimacy, ${ }^{6}$ through their suffering. Their deaths in the universal experience of childbirth mark them as deserving of humanitarian and political attention. Yet within their own countries, for countries such as Tanzania, the deaths of pregnant women continue to present a stubborn problem. The Millennium Development Goal 5A, to reduce maternal mortality by three-quarters from the 1990 levels by the program's end date in 2015, was one of the primary remaining goals. Tanzania, and many other countries, particularly in sub-Saharan Africa, failed to meet these goals, making some progress but not enough. Even then, the numbers that policy makers and public health practitioners, statisticians and demographers used to calculate these ratios and their changes are deeply and fundamentally flawed.

The bottom line is that for every country maternal mortality remains a question, asking leaders, "Whose lives do you value, and what level of death is acceptable for marginalized women?" Fundamentally, maternal mortality on the global scale is about the value we attach to women's lives and to which women's lives. Secondwave feminism in Western countries, and the United Nations Decade for Women from 1976 to 1985 , were significant drivers in the initial push to elucidate the true extent of maternal deaths, numbers that, when first published, shocked many.7 Not until the mid-197os did the world even have its first glimpse of the extent of the global burden of maternal mortality. In 1987, the then-director general of the World Health Organization, Halfdan Mahler, wrote, "[Maternal mortality] has been a neglected tragedy; and it has been neglected because those who suffer it are neglected people, with the least power and influence over how national resources shall be spent; they are the poor, the rural peasants, and, above all, women." Despite the passing of more than thirty years, this statement remains just as valid today as it was then. Some countries have been able to invest significant resources in reducing maternal deaths, supported and pushed by robust political will. Many other lower-income countries continue to struggle because of extensive competing demands on their resources.

Since the 1990s, the global community has come to see maternal mortality as a human rights issue. Several groups have attempted to formulate a so-called rightsbased approach to reducing maternal mortality, incorporating this language into the Sustainable Development Goals. Carla AbouZahr writes that maternal mortality does not have an easy target for eradication, like a pathogen or vector, making it a more diffuse public health challenge, but also that "failure to take action to prevent maternal death amounts to discrimination because only women face the risk." Because of the necessary and absolutely normal act of biological reproduction, women will always need care during pregnancy and while giving birth; their lives will always be hanging in the balance of these care practices.

Though pregnancy is not an illness under most normal circumstances, strikingly large biobureaucracies have emerged, seeking to provide care in those times when pregnancy and childbirth deviate from the biologically determined norm. 
States have employed biobureaucratic institutions for functional and idealistic ends. The expansion of these biobureaucracies has brought with it and, in fact, created scarcity through implementation of labyrinthine procedures for accessing even the supplies and expertise available. Biobureaucracy has also generated a different form of scarcity, a scarcity of affective, intersubjective caring that meets patients' expectations and desires. The space for these forms of caring has shrunk to accommodate the reams of paperwork and documentation accompanying technical care's protocols and best practices. Maternal health and death in Rukwa provide a particularly poignant perspective on the expansion and functioning of these biobureaucracies globally as policies and advocacy campaigns now tell women and their families that giving birth in biomedical facilities is the only responsible choice. The insinuation is that giving birth anywhere else, purposefully or not, not only is irresponsible but can lead directly to a woman's death; hospitals like Mawingu can save a woman so long as she knows the right way to use them. And yet, so many of these institutions globally still fail women every day.

\section{THE INVISIBLE HANDMAIDENS OF SAFE MOTHERHOOD}

Even as national and global governing bodies around the world recommit to reducing the deaths of women during pregnancy and childbirth via targets in the Sustainable Development Goals, those who are most responsible for delivering on these promises are nearly invisible. Their work environments are often chaotic and unsafe, undignified and structurally violent. Nurses diligently toil away for years without promotion, recognition, or praise, let alone access to additional training or skills maintenance programs. They improvise and improvise and improvise until the actual guidelines are a figment of the imagination, an impossibility thought up in far-off places. In the interstices, nurses and doctors themselves get married, give birth, become ill, conduct business, care for parents and relatives, and work to sustain themselves and their children. They are on the front lines of clinical and affective care, engaging in practices of care that demand everything of them unless they put up walls and barriers, walk more slowly, respond less quickly. Each and every time they step into their workplace, they must be ready to compromise or weigh their different professional values, ethics, and morals, so forcefully does their environment preclude so many standard operating procedures and clear-cut pathways to something called good care.

For the nurses and doctors working in places like Mawingu Regional Hospital, maternal mortality is also implicitly about the building and re-formation of their ethical selves in varying circumstances, negotiating values of life and communalism at odds with a biomedical system and world created by capitalism and colonialism that privilege certain lives over others. Worse, it is a system that forces individuals to make the choice about whether their own life or that of a stranger is 
worth more. This ethical choosing and its attendant quandaries contribute to the continuance of maternal deaths in these low-resource settings. Maternal deaths continue to occur because the system has been organized to privilege the appearance of accountability, the documentation of it, over the actual, radical change necessary for a real kind of accountability that does justice to women's lives and to their communities. Caught in the crosshairs of competing demands and systemic desires for appearance and form over substance, maternity care providers are in an impossible position-often asked by policies to choose between protecting themselves or protecting the women they serve. The benefits of serving themselves second are lost in a system that, as time moves forward, increasingly devalues their service and overall contributions to society as civil servants and guardians of the lives of others. Arrangements in which more and more work at higher and higher quality are expected with fewer and fewer resources push efficiency to its limits and beyond. The spaces left for thoughtful, compassionate care are compressed ever further until they are imperceptible even to the carers themselves, let alone to the women who rely upon them.

\section{PUTTING THE CARE PROVIDERS BACK IN \\ HEALTH CARE}

While others have sought to put the " $\mathrm{M}$ " back in $\mathrm{MCH}$ (maternal child health) or the "mother" back in Safe Motherhood, I started from a different point entirely. ${ }^{10}$ I have sought to put the care providers back in health care because interventions have come to target improving the skills of biomedical providers as the current key to preventing maternal deaths. These people, the biomedical providers, are the ones who "would encounter the failing pregnant, or birthing bodies." while anthropologists have been busy conducting research with women and their families, exploring the meanings of pregnancy and birth, they have inadvertently flattened out the portrayals of health care personnel. Researchers have separated these providers from their social connections and their broader political economic milieu, even while working hard to explicate these very factors and their influences in the lives of pregnant women. The direction of policy has not shifted to be more woman centered; if anything, the new Sustainable Development Goals and the new Strategies toward Ending Preventable Maternal Mortality focus even more explicitly on health care facilities, promoting systems approaches to improving care and reducing deaths. ${ }^{12}$ Yet much work must still be done to build more comprehensive and accurate understandings of how maternal health care providers are just as embedded as women and communities in networks and systems that fundamentally affect maternal deaths. Those networks and systems shape their care practices and what they are able to offer to their patients.

In September 2016, the Lancet published a series on maternal mortality that focused on "the mismatch between burden [of maternal death] and coverage" of 
biomedical health care services for women and girls. ${ }^{13}$ This mismatch also reveals how global health has failed to accurately understand and harness the experiences of both patients and providers, leading to a disconnect between plans and actual needs of people on the ground. ${ }^{14}$ That, then, is what I have sought to do here by demonstrating that even though policy planners or experts at the $\mathrm{WHO}$, in charge of designing recommendations for best practice, and the nurses and doctors at Mawingu Hospital share a belief in the powers of biomedicine, a wide gulf separates them. According to Lynn Freedman, who contributed to the Lancet series, "The point is not that global strategies, evidenced-based guidelines, or high-level monitoring and accountability initiatives are inherently wrong or unnecessary. But when they consume most of the oxygen in the room, drowning out voices and signals coming from the ground, they distort both understanding and action." ${ }^{15}$ Here I have presented an alternative perspective that has made clear many of the forces behind deviations from WHO or Tanzanian Ministry of Health guidelines and initiatives regarding maternal deaths. It also shows that systems much larger than one hospital have, in fact, necessitated these deviations and continue to incentivize accounting for these deviations over actually improving care in significant and lasting ways.

\section{THE COMPLEX REACH OF SCARCITY AND IMPERFECT CARE}

The scarcity with which nurses and doctors struggled every day generated a perception that ideal care was nearly impossible to provide. This environment led to reduced expectations that providers and hospital administrators could solve clinical or systemic problems, constrained as they were by a system that currently, and historically, made it so difficult to do so. As providers worked in an environment of scarcity and simultaneously within a complex of demands for data collection and metrics, improvisation and the justification of deviation from guidelines became part of their everyday lives. They shifted their efforts from providing care to accounting for deviations from ideal care, which was set out in guidelines and standard operating procedures generated in other parts of the country or world. Good outcomes often happened by chance and could not be replicated, defying the bureaucratic policies and procedures in place meant to standardize, with the consequence of uneven, unpredictable results. An accounting culture, focused on justifying deviations from high-quality care or on collecting data, and undergirded by the power of a global system, worked hard to replace a caring culture, one in which both patients and hospital staff members received the types of care they needed in order to survive and thrive.

Nurses provide the vast majority of the care to pregnant women but often have minimal power within the hospital hierarchy-their efforts often were undervalued and overlooked. They used alternative means to try to gain certain outcomes 
or resources for their patients, drawing on informal routes to influence or social capital by manipulating documents or by other means. An institutional lack of care contributed to the continued production of nursing care that gave the appearance of lacking motivation and compassion as nurses said they were demoralized by their lack of visibility within the hospital structure. The care that nurses were able to provide and the care practices in which they engaged were also influenced by the demands of their personal lives, which they were not always able to leave behind them when they left their homes for work. Interactions with hospital administrators conditioned nurses to be secretive and self-regulatory when they made mistakes in care, further producing an environment in which staff members and administrators did not engage in open discussions about care practices and nurses' needs but produced robust forms of informal accountability.

Health care providers at all levels were forced to modify, improvise, and cut corners so that women got at least some care, care that was good enough. ${ }^{16}$ The constraints of their work environment produced conditions that were not amenable to quick action or early intervention; the nurses and doctors came to see early, efficient intervention as a near impossibility. In some cases, global guidelines about respectful maternity care might hold nurses in violation of the idealized forms of practice-for instance, when they yelled at a woman in labor or hit her legs because she was not exerting enough effort or paying enough attention to critical instructions. But in their everyday ethics, nurses believed they were indeed caring for women, employing such practices solely for the purpose of making sure a woman's baby emerged alive in an environment with few technical alternatives: What good were kind words and comforting touches if a woman's baby was stillborn?

Sometimes, however, patients' negative interactions with nurses, which they did not always fully understand, undermined their trust in the system. Women entered the hospital setting after a lifetime of gender inequity and differential access to education, respect, and decision-making powers. They came to the ward conditioned by their own stories, and those of other women, about biomedical providers-stories that too frequently centered on cases of abuse, neglect, negligence, or corruption. Collective memory recited stories of blood being sold to families when a life was on the line, or of village nurses telling families they needed to buy gloves and then magically producing a pair for sale, or they conjured images of drivers carrying pregnant women's lifeless bodies back home, limbs strapped to limbs to keep the corpse on the back of the motorcycle.

In villages, on the hospital ward, and on the national stage, Tanzania continues to play out the battle first recorded in the colonial era: What is the proper site for childbirth - the home or the hospital? While global public health studies and interventions have disavowed the skills, knowledge, and social roles of local midwives, they have less critically accepted young, barely trained health care providers in the biomedical tradition. Because it is nearly impossible to predict who will develop a complication during an otherwise problem-free pregnancy and 
childbirth, the government and the global community have adopted the stance that every woman should be under the supervision of institutional biomedical care. In the colonial era, the biggest barrier to allowing all women to give birth in facilities was a lack of trained personnel and a lack of infrastructure, buildings, to accommodate so many women. Nearly eighty years later, the same problems continue to plague the Tanzanian government, whose push to send women to institutions has outpaced its recruitment and support of the necessary providers. Penalizing home birth by charging fines to those who do not manage to give birth in a health facility, whether by accident or by intent, serves no purpose other than fostering additional ill-will in communities with already strained relations between women, their families, and health care providers.

Governments and NGOs alike seem to be looking for quick fixes, for the magic bullets that will stop the more than eight thousand maternal deaths that occur in Tanzania every year and send shock waves through families and communities. Yet maternal health is a systemic problem, and when a woman dies in a health facility her death is a culmination of all the structures that have influenced her life to that point. Her death is also a product of the complex, bureaucratic, and socially tense environment of the facility itself. Sending ever-increasing numbers of women to facilities will do nothing to reduce the numbers of women dying when those facilities are poorly stocked, suffer from supply chain problems originating at the national level, have inadequate funding mechanisms due to the unequal effects of decentralization, and systematically perpetrate violence against the staff members by keeping them living in poverty, subject to abuse by superiors, denigrated on the basis of their gender, and shut out from crucial information because of poor communication, lack of transparency, and lack of respect. After all, without the supplies and skills, a hospital is just a guesthouse-full of beds and nothing else; as an environment for giving birth, it is, essentially, no better than home.

Biomedicine and biobureaucratic expansion continue to determine which pregnant bodies deserve biomedical assistance, where these same bodies should be allowed to give birth, and with access to what personnel and what resources. The bounds, limits, and acceptable forms of ethical biomedical caring for pregnant women were long ago determined and continue to produce many challenges and conflicts within both communities and biomedical institutions. Ethical care on the Mawingu maternity ward is shaped and reshaped by the community, individual patients' families, nurses' and doctors' families, individuals' religious beliefs and practices, codified professional ethics via medical ethics, the nursing association's Code of Ethics, and invocations of Florence Nightingale, paragon of nursing care, as well as by informal ethics based in the communalism of the health care professions and the interdependence at the heart of social living in Tanzania. Nurses and doctors, as well as health administrators, must balance all of these ethical forms and systems, as well as the ambiguities and personal discretion involved in each encounter, during each intersubjective negotiation or confrontation. The providers 
are forced to action in the provision of care on a daily basis, but they both enact and resist certain forms of care and certain forms of ethics through subtle means as they are engaged in the practices of caring. The object of resistance is variously the patient, the hospital, the hospital's administrators, the health care system at large, or even the out-of-touch global protocols structuring nearly everything but impossible to fulfill. These intersubjective ethical negotiations become vital to providing clinical care that saves women's lives or that lets others slip through the cracks and drift away into death. Policy and public health approaches to explaining the ongoing burden of maternal mortality, and solutions to address it, are utterly unequipped to capture these everyday ethics and care practices that so profoundly shape women's outcomes via the functioning of the system as enacted through the bodies and minds of health care workers. 